\title{
Deliberative research as a tool to make value judgements Tania Burchardt
}

\section{Contents}

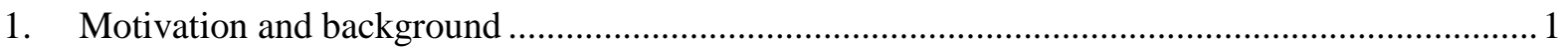

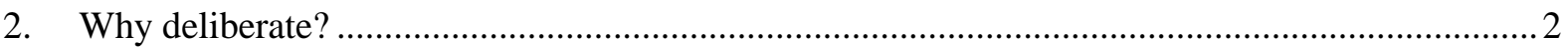

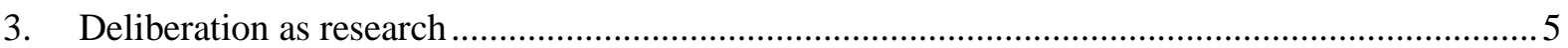

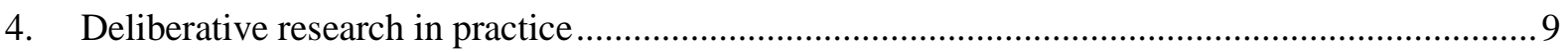

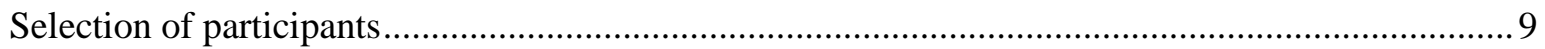

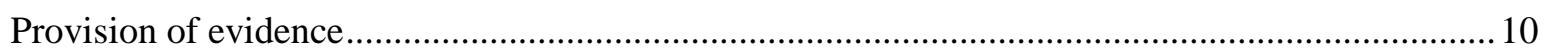

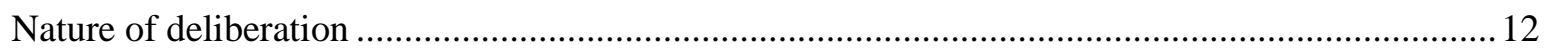

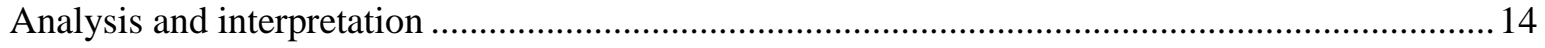

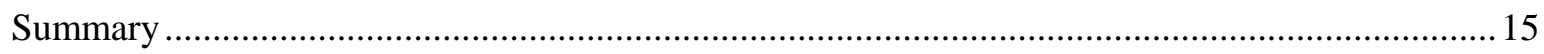

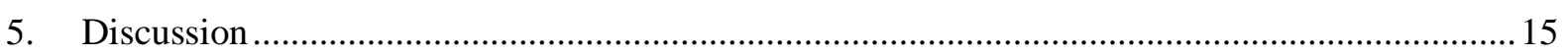

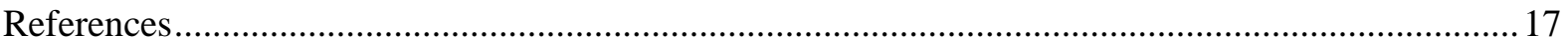

CASE/159

April 2012
Centre for Analysis of Social Exclusion London School of Economics

Houghton Street London WC2A $2 \mathrm{AE}$

CASE enquiries - tel: 02079556679 


\section{Centre for Analysis of Social Exclusion}

The Centre for the Analysis of Social Exclusion (CASE) is a multi-disciplinary research centre based at the London School of Economics and Political Science (LSE), within the Suntory and Toyota International Centres for Economics and Related Disciplines (STICERD). Our focus is on exploration of different dimensions of social disadvantage, particularly from longitudinal and neighbourhood perspectives, and examination of the impact of public policy.

In addition to our discussion paper series (CASEpapers), we produce occasional summaries of our research in CASEbriefs, and reports from various conferences and activities in CASEreports. All these publications are available to download free from our website. Limited printed copies are available on request.

For further information on the work of the Centre, please contact the Centre Manager, Jane Dickson, on:

Telephone: $\quad \mathrm{UK}+2079556679$

Fax: $\quad$ UK+20 $\quad$ J9556951

Email: $\quad$ j.dickson@1se.ac.uk

Web site: http://sticerd.lse.ac.uk/case

(C) Tania Burchardt

All rights reserved. Short sections of text, not to exceed two paragraphs, may be quoted without explicit permission provided that full credit, including (c) notice, is given to the source. 


\title{
Editorial Note and Acknowledgements
}

Tania Burchardt is a Senior Lecturer in the Department of Social Policy, and Deputy Director of CASE, at the London School of Economics (t.burchardt@lse.ac.uk).

Ellen Stewart provided very valuable and skillful research assistance during the early phases of this work. Polly Vizard is the co-architect of the equality measurement framework, for which we carried out the deliberative exercises reflected on in this paper, and I have benefitted enormously from countless discussions with her over the years about the capability approach and deliberation. Ellen and Polly also provided thoughtful comments on a draft paper, as did Rikki Dean and Abigail McKnight, and I am indebted to them all. Errors of fact or judgement remain of course entirely my responsibility.

The research for this paper received no specific grant from any funding agency in the public, commercial, or not-for-profit sectors. Earlier work involving deliberative research, on which this paper reflects, was funded by the Equalities Review, the Economic and Social Research Council and the Equality and Human Rights Commission.

\begin{abstract}
The 'deliberative turn' in democratic theory has generated a wealth of deliberative experiments. The purpose of deliberation as a research technique (as opposed to policymaking or public consultation) is distinctive: to uncover the public 's informed, considered, and collective view on a normative question. In the social science context, this often arises in relation to research on poverty, well-being and inequality, where there is a need to define and justify the thresholds and concepts adopted on a deeper basis than convention alone can offer. This paper compares deliberative research to more traditional methods of studying the values of the general public, such as in-depth interviewing, attitudinal surveys, and participatory approaches, and reveals that deliberative designs involve a number of assumptions, including a strong fact/value distinction, an emphasis on 'outsider' expertise, and a view of participants as essentially similar to each other rather than defined by socio-demographic differences. Normative decisions permeate the design and implementation of deliberative research, so while it has the potential to provide uniquely considered, insightful and welljustified answers to the problem of defining a collective position on key questions in social science, transparency at all stages of the process is essential.
\end{abstract}

Keywords: Deliberative research; value judgements; capability approach; inequality; research design.

JEL classification: B50 


\section{Motivation and background}

Many problems in social science require decisions to be made which are value-laden. This is particularly the case in relation to research on poverty, well-being, quality of life and related concepts. For example, what is an 'adequate' standard of living? What aspects of life are relevant to an overall assessment of well-being? How should the different components of a multi-dimensional measure of poverty be combined? What is an appropriate trade-off between length and quality of life in calculating a QALY? Confronted with these problems researchers have a number of options. They may attempt to justify a decision with respect to a "scientific" criterion (for example, Gordon, 2006) or impose their own judgement and acknowledge its arbitrariness (for example, Burchardt, Le Grand and Piachaud, 1999), or refer to an equally arbitrary convention (for example, Trinczek, 2007). Even when combined with sensitivity testing to check the robustness of the conclusions to different plausible values, any of these options is associated with a significant degree of embarrassment and a sense that it threatens to undermine the impact of the research, if not its validity. One increasingly popular strategy to overcome this obstacle is to undertake deliberative research with the general public, to elicit their views and value judgements, thereby, apparently, absolving the researcher of responsibility for the decision that is made.

However such a strategy raises a number of important questions. Why, and in what circumstances, is deliberative research a better technique for eliciting the values of 'ordinary people' than other methods, such as in-depth interviews, large-scale attitudinal surveys or participatory approaches? How should deliberative exercises be designed to maximise their validity and reliability and minimise the risks of various sources of bias? Do the results really get researchers 'off the hook' when it comes to making value judgements?

These questions form the focus of this paper, with particular application to the problem of specifying and justifying a list of central and valuable capabilities, that is, a list of the priorities for public policy or for evaluating a given state of affairs, expressed in terms of the things that people are able to be and to do in their lives (their (capabilities'). Examples include, 'being healthy' or 'being able to go out without shame'. The problem of how to define such a list has been much discussed in the capability approach literature. According to one of the leading theorists, Martha Nussbaum, a list of central human capabilities with purportedly universal application at a general level can be developed through a priori reasoning, and she has provided such a list (Nussbaum, 2002). This is in contrast to the position advocated by Amartya Sen, who argues that the capabilities to be prioritised in any given context should be identified through a process of democratic public debate, scrutiny and criticism (see, for example, Sen, 1999). However, as Alkire (2002) observes, Sen does not describe through what particular mechanisms public deliberation on the selection of capabilities is to take place, nor does he fully address the difficulties of constructing democratic forums within undemocratic or grossly unequal societies. This lack of specificity has led to a number of attempts to clarify the role for democratic and 
participatory processes in Sen 's capability approach, both in theory and in practice (especially Crocker, 2003, 2006, 2007).

Our own work (Burchardt and Vizard, 2011) on the construction of a capability list took place in the context of the development of an Equality Measurement Framework for Britain in the $21^{\text {st }}$ century, and included two phases of deliberative workshops with the general public and with individuals and groups at particular risk of discrimination and disadvantage. Fieldwork was carried out by the social research institute of IpsosMORI (2007). It was initiated by the Equalities Review in 2007, an independent committee appointed by the then Prime Minister Tony Blair, and subsequently continued under the auspices of the Government Equalities Office (GEO) and the Equality and Human Rights Commission (EHRC).

In the course of designing and implementing our method for specifying a capability list, fit for the purpose of monitoring the (lack of) progress towards creating a more equal society in Britain, we encountered a number of theoretical and methodological challenges. This paper reflects on the problems relating to the deliberative components of the method. It also draws on interviews with three of the leading research organisations in the UK using deliberative methods and with the then head of Government Social Research, which we carried out subsequent to our own deliberative exercise in order to understand more about the uses to which these techniques were being put in a range of policy-relevant contexts. The purpose of this piece is not to report in detail on the findings of our own deliberative exercise but rather to use it as an example with which to discuss the potential, and limitations, of deliberative methods as an approach to eliciting value judgements in social science.

\section{Why deliberate?}

The theoretical roots of deliberative research lie in political philosophy - an unusual origin for a social scientific tool. Developments in democratic theory around two decades ago shifted the understanding of democracy as a system of aggregating conflicting preferences towards considering it as a process of preference formation and transformation, brought about through communication between informed and respectful equals (Dryzek, 2010). Deliberative democrats emphasise that policies should be justified through the exchange of reasons and arguments relevant to all, rather than being the result of competition between private or personal interests where the most powerful lobby wins out (Weinstock and Kahane, 2010). This has a number of implications, for example that citizens ' participation in debate is essential, including becoming better informed and encountering contrasting points of view, as opposed to merely expressing pre-formed opinions through the ballot-box.

The GEO has responsibility for coordinating and promoting the government's strategy on equality, while the EHRC is a statutory, publicly-funded body at arm's length from government, with a mandate to protect and promote equality and human rights in accordance with the Equality Act 2006. 
The conditions in which such 'public reasoning' can take place have been much discussed (Fraser, 1989; Young, 2000; Richardson, 2002; Dean, 2009), and it is recognised that deliberation in practice is unlikely to reach the 'ideal speech situation' described by Habermas (1996): "free from domination, coercion, manipulation and strategising" so that "the only power remaining is that of the better argument." Nevertheless these theoretical foundations have prompted, directly or indirectly, several experiments in real-world deliberative democracy. Perhaps the most widely known is participatory budgeting, begun in Porto Alegre in Brazil in 1989 and subsequently applied in various forms all over the world (Baiocchi, 2003; de Sousa Santos, 2005). Preparatory meetings in local neighbourhoods on various issues of concern precede plenary sessions to decide the city budget.

A number of claims are made for such exercises, including that they strengthen citizens ' power in decision-making, especially among disadvantaged sections of the population; that they embody open and transparent government; and that they enhance the legitimacy of the decisions reached (Cabinet Office, 2006; Michels, 2011; Searing et al, 2007). These can broadly be classified as 'intrinsic democratic' justifications for deliberative policymaking. Claims are also made for the potential of deliberative forums to increase accountability (Involve/NCC, 2008; OLR, 2007) but Parkinson (2006) observes that even where policymakers are held accountable for their decisions to the participants in a deliberative consultation (which is the exception rather than the rule), the participants' own lack of accountability to the wider population limits the overall gain in accountability.

In other instances, deliberative exercises have accompanied policymaking processes, rather than being the sole input. For example, in the UK, the body that issues guidance on the cost-effectiveness of new drugs and treatments, the National Institute for Health and Clinical Excellence (NICE), incorporates a standing 30-member citizens ' council. The long-run commitment of participants facilitates the acquisition of expertise, both technical and procedural, but the number of individuals involved is small (Davies, Wetherell, and Barnett, 2006). In contrast, the Department for Work and Pensions organised a one-off large-scale deliberative summit, at which over 1000 members of the general public deliberated on the four options presented in the Pensions Commission report (DWP, 2006). The results fed into the government's response to the Commission. This might perhaps be more accurately classified as a form of public consultation, rather than policymaking per se.

The stated rationales for deliberative consultation, as distinct from policymaking, are often more pragmatic - for example, that including public deliberation improves the quality and breadth of information on which decisions are made and hence the effectiveness of the policies devised (Bennett et al, 2004). In addition, they may emphasise the instrumental democratic gains, in terms of increasing participants ' confidence, especially finding a 'voice' in a public forum; building a (sustainable) network among participants; promoting social cohesion through increased understanding between people with diverse values and backgrounds; fostering working relationships between stakeholder groups and government; and building 
public trust in government (Cabinet Office, 2006; Michels, 2011; Searing et al, 2007; Wakeford, and Singh, 2008).

Genuine consultation is a two-way process. But a number of deliberative exercises, perhaps particularly on scientific and technical topics, are best seen as promoting public engagement in an existing policy, or even as part of a government communication strategy, for example the GM Nation debate (Rowe et al, 2005). Developing a communication strategy for an existing policy through deliberative means could include gaining information about the acceptability of different policy options, and whether participants' attitudes change in response to different forms of presentation of the policy. OLR (2007) note that staging a deliberative event is a 'media-friendly' form of activity, because it offers ready access to video footage and interviews with 'ordinary people'. This may be a legitimate activity for government, but the conflation of such publicity stunts with more serious deliberative undertakings threatens to give deliberation as a whole a bad name, and to undermine the instrumental democratic benefits claimed for deliberative consultation.

Yet other deliberative forums have tackled policy questions from outside the formal policymaking process, such as citizens juries run by think-tanks and pressure groups on issues as diverse as child poverty (Fabian Society, 2005) and rationing healthcare (Lenaghan, 1999). The objective here is to elicit information about the public 's views on the subject under discussion, and then present the results to a wider audience, including to policymakers and other stakeholders. The justifications overlap with deliberation as policymaking and deliberation as consultation, but the less closely a deliberative exercise is tied to a policymaking process, the more it begins to look like research. Indeed deliberation is increasingly used as a standalone research technique. Again a range of descriptors is used, including deliberative workshops, focus-groups, polls, and consultation. The core rationale for deliberative research is to uncover the informed, considered, views of members of the general public, often on complex issues to which they may not previously have given much attention.

The roles of deliberation as policymaking, as consultation, public engagement or communication, and as research are not always as carefully delineated as they should be, which has produced some mistaken claims and criticisms. Evans and Kotchetkova (2009) observe that in the context of scientific issues, deliberative exercises often blur the boundary between academic research and promoting public engagement. Indeed the 'research' component may be reduced to ensuring that the best possible conditions for deliberation are provided and reporting the conclusions of the exercise (Evans and Kotchetkova, 2009, p640). I want to argue here that deliberative research does have a distinctive role to play, provided its purpose and particular application are wellaligned.

A number of authors offer sets of criteria against which deliberative exercises should be assessed. For example, Papadopoulous and Warin (2007) highlight the need to scrutinise openness and access, quality of deliberation, efficiency and effectiveness, and transparency and accountability, while Gutmann and Thompson (1996) focus on 
reciprocity, publicity and accountability. Chilvers (2008) summarises his criteria as representativeness, inclusivity, clarity, transparency, legitimacy, adaptability, learning and efficiency. However as we have seen, there is a spectrum of purposes of deliberative exercises from direct policy-making, through public consultation or engagement, to research on public values, with a different blend of rationales for engaging in deliberation associated with each purpose. Most of the criteria developed in the literature refer to deliberation as a form of democratic decision-making (direct or indirect), rather than as a form of research. There remains a need to develop an understanding of how the quality and appropriateness of deliberative exercises as part of research projects can be assessed, and specifically in the context of projects intended to elicit the values of members of the general public.

\section{Deliberation as research}

The numbers of participants, recruitment procedures, duration of involvement, structure and content of the process, and types of analysis and interpretation vary widely within and between forms of deliberative research, including deliberative workshops, focus-groups, polls, and 'consultation'. Deliberation may therefore be best characterised as an 'approach' to research, rather than as a specific method. The deliberative approach has three features, derived from its theoretical underpinnings, that distinguish it from other types of research. Firstly, the aim of the research is to reach people's informed and considered judgements and underlying values in relation to the subject in hand, through a process of public reasoning. Public reasoning implies, as a minimum, encounters with contrasting points of view and a requirement to justify opinions through arguments which make sense to others (Rawls, 1997). Secondly, the process involves researchers providing information (sometimes written, but often through experts available for questioning) to participants about the subject under discussion. Thirdly, and related to the preceding points, there is an expectation that the beliefs and values of participants may be transformed by involvement in the research. The intentional and direct input of new information by researchers and the assumption that participants ' views may change as a result of the exercise, stands in contrast, of course, to the efforts made in most other qualitative research modes to facilitate discussion and elicit participants' views while minimising the extent to which the researcher's presence and activity 'pollutes' the field of study.

How then does deliberative research compare to other techniques which are commonly used to study people's values? Table 1 provides a summary. Deliberative research is perhaps closest to participatory research. All deliberative research is participatory in the sense that participants are active in the research process and operate, at least in part, through a collective forum. In both instances, there is an expectation that participants' views may be transformed by the research itself - in the case of deliberative research, through new information and encounters with the arguments of others, and in the case of participatory research, through the emancipatory effect of an empowering process. Nevertheless in deliberative research, the research questions, methods (including selection of participants), and the form of 
the output, are often defined by an external authority such as the researcher or funder and it therefore does not fulfil Chambers ' (1997) definition of fully participatory research. Many participatory exercises fall short of this ideal but the greater the control participants have over the process, the more participatory it is, while for deliberative research there is no such objective. For example, the Deliberative Polls devised by Fishkin (2009) follow a highly specific formula, based on a standard opinion survey issued to a random sample, followed by deliberation in small groups with carefully balanced briefing and access to experts for questions, and finally a second survey to establish the extent of change in participants ' views. This is a far cry from the participatory research paradigm. Some attempts have been made to define and put into practice 'bottom up' deliberation (Wakeford, 2007; Wakeford and Singh, 2008), but this is by no means the norm.

Moreover, not all participatory research is deliberative: participatory exercises often do not include the provision of information by the researcher or external 'experts' and indeed the participatory paradigm challenges the notion of external expertise altogether: "There are 2.8 billion poverty experts, the poor themselves. Yet the development discourse about poverty has been dominated by the perspectives and expertise of those who are not poor: professionals, politicians and agency officials. This book seeks to reverse this imbalance by focusing directly on the perspectives and expertise of poor people" (Narayan, 2000, p2). Displacing officially recognised knowledge and expertise and replacing it with lived experience of the disadvantaged is at the heart of the participatory enterprise. This is in contrast to deliberative processes, which explicitly aim to inject 'evidence' - usually defined as such by the researchers not the participants - into the discussion, to ensure that the deliberations are 'wellinformed'.

Discussions in participatory forums do not necessarily proceed through public reasoning and the identification of distinct interests and values is an important function of the research, facilitated by separate discussions with different groups - for example, men and women, young and old, 'uppers' and 'lowers' (Narayan, Prtichett and Kapoor, 2009). Again, this is in contrast to the deliberative ideal, where the objective is to create encounters between equals with divergent viewpoints and facilitate exchange of reasons leading to a common final position.

So while both deliberative and participatory research involve collective discussion, and both seek to uncover the considered views of the participants, they diverge in terms of who sets the agenda (at least in the ideal case), the role of external expertise, and the intended endpoint (the identification of difference or the generation of consensus).

Compared to deliberative approaches, more traditional methods to study people 's values such as in-depth interviews and large-scale attitudinal surveys offer limited opportunity for respondents to reflect on their own position, and they do not involve encounters with the views of others. Consequently the opinions expressed may not be very deeply considered, particularly if the subject matter is unfamiliar to the 
respondent, and since there is little scope for the provision of additional information or evidence, they may also be poorly-informed. ${ }^{2}$ But whether these characteristics are considered strengths or weaknesses depends crucially on the objective of the exercise. If the purpose of eliciting the views of respondents is to understand how the general public will behave (for example, their voting intentions or their commitment to recycling), the unmediated, untransformed opinions expressed through in-depth interviews and attitudinal surveys are likely to be a better guide than the highly processed and contingent views expressed at the close of an intensive deliberative workshop. As Fishkin (2010) notes, deliberation produces, "a representation of what the public would think under good conditions for thinking about it" (p196, emphasis added). This is quite different from understanding what the public do think - for which purpose in-depth interviewing or attitudinal surveys are certainly preferable.

Table 1: Deliberative research compared to other techniques to study people's values

\begin{tabular}{|c|c|c|c|c|}
\hline & $\begin{array}{c}\text { Typical } \\
\text { sample size }\end{array}$ & Core purpose & $\begin{array}{l}\text { External } \\
\text { information } \\
\text { /expertise } \\
\text { provided }\end{array}$ & $\begin{array}{l}\text { Engagement } \\
\text { with the views } \\
\text { of other } \\
\text { participants }\end{array}$ \\
\hline $\begin{array}{l}\text { Deliberative } \\
\text { research }\end{array}$ & 10 s to $1000 \mathrm{~s}$ & $\begin{array}{l}\text { Consensus } \\
\text { through public } \\
\text { reasoning }\end{array}$ & $\mathrm{Y}$ & $\mathrm{Y}$ \\
\hline $\begin{array}{l}\text { Participatory } \\
\text { research }\end{array}$ & $10 \mathrm{~s}$ to $100 \mathrm{~s}$ & Empowerment & $\mathrm{N}$ & $\mathrm{Y}$ \\
\hline $\begin{array}{l}\text { In-depth } \\
\text { interviews }\end{array}$ & $10 \mathrm{~s}$ & $\begin{array}{l}\text { Qualitative } \\
\text { analysis of } \\
\text { difference }\end{array}$ & $\mathrm{N}$ & $\mathrm{N}$ \\
\hline $\begin{array}{l}\text { Attitudinal } \\
\text { surveys }\end{array}$ & $1000 \mathrm{~s}$ & $\begin{array}{l}\text { Quantitative } \\
\text { analysis of } \\
\text { difference }\end{array}$ & $\mathrm{N}$ & $\mathrm{N}$ \\
\hline
\end{tabular}

In addition there are fundamental epistemological differences between deliberative research and both attitudinal surveys and in-depth interviewing. Attitudinal surveys indeed all large-scale surveys - draw on a positivist paradigm, incorporating the assumption that there are facts 'out there' to be discovered, including for example facts about poverty as well as about what people think about poverty. In-depth interviewing is more usually associated with a interpretativist perspective, in which meaning is assessed from the person's own point of view and what is held to be true is

2 Focus groups do involve encountering the views of others, and some also incorporate prompts or aids for discussion. However the short duration of most focus groups and the minimal external input limit the extent to which a transformation of participants' beliefs or values is likely to take place. 
generated through interaction between people (Habermas, 1967). What constitutes poverty, then, is socially constructed, and people's attitudes towards poverty are contingent upon particular social interactions and dialogue. Deliberative methods appear to occupy a middle ground between these two poles. On the one hand, the information provided, for example through expert evidence, is often treated in a positivist sense as being about the world 'out there': even if evidence can be disputed, these are disputes about the state of the world. On the other hand, the considered values of the participants are often held to be generated and articulated only through engagement with others. Not all deliberative exercises characterise participants' values in this way; large-scale deliberative polls, for example, appear to adopt a more thorough-going positivism, with participants ' underlying values already in existence and being revealed through reasoned debate. But the Habermasian origins of deliberation would certainly imply that the process is constitutive of participants' values, not merely a means of articulating them.

We have seen, then, that the choice of deliberation as a research design involves a number of epistemological and normative commitments, even before the particular exercise has been defined. In many cases, it depends on maintaining a fact/value distinction, with one foot in a positivist camp along with attitudinal surveys and the other with the social constructivists and in-depth interviewing. Like participatory research, it prioritises a collective process, but unlike participatory research, and indeed the more traditional methods, the objective is the identification of a consensus rather than analysis of individual or group-level differences. Outsider knowledge and expertise is valued as a necessary contribution to the information set for insiders, in contrast to the participatory research paradigm, although deliberators are assumed to be capable of sophisticated reasoning and judgement - qualities which are not usually called upon in respondents to more traditional modes of research such as in-depth or survey interviews.

Given this unique orientation, we might expect deliberative research to be especially useful where establishing a collective position is more important than understanding differences between subgroups, and where the objective is to obtain considered, informed opinions on the subject in hand, rather than to extract information on attitudes which will be useful as a guide to people's behaviour. The tasks of identifying a consensus on appropriate thresholds for poverty, or a list of central and valuable capabilities that should be a priority for public policy, appear to fit these criteria. So despite the limitations revealed by scrutiny of the foundations of deliberative research, its potential for ascertaining public value judgements remains. We now turn to consider whether deliberative research in practice lives up to its theoretical promise. 


\section{Deliberative research in practice}

Conducting deliberative research involves making a series of important methodological decisions, which can be summarised under the headings of selection of participants, provision of evidence, nature of deliberation, and analysis and interpretation. The choices made have a significant influence not only on the research process, I shall argue, but also on the likely outcomes.

\section{Selection of participants}

The number of participants in deliberative exercises ranges from a dozen members of a citizen's jury up to deliberative summits of 1000 people. Several studies note a trade-off between the quality of discussion that can be achieved in small groups and the representativeness or spread of opinion made possible by larger numbers (Smith and Wales, 2000; Michels, 2011; White et al, 1999). Papadopoulous and Warin (2007) characterise it as a tension between 'participationists', who emphasise inclusion and representativeness, and 'deliberationists', who emphasise the quality of the discussion.

The number of participants is related to the question of how they are sampled. There is a spectrum of representativeness, from statistically representative deliberative polls, via purposive sampling and small non-random groups, to self-selection or use of preexisting groups. Dienel (1999) and Fishkin and Luskin (2005) favour random sampling in order to be able to test statistical significance and produce generalisable results but Wakeford (2007) rejects statistical representativeness because it reproduces the minority status of groups who are already marginalised. In many cases, participants are recruited because of particular roles they occupy - for example, as patients or service users - or because of their socio-demographic characteristics, for example to address Wakeford's concerns by 'over-sampling' minority groups. However both these strategies carry risks. Evans and Kotchetkova (2009) report an experiment comparing a deliberative workshop with focus groups composed of patients, carers and lay citizens, evaluating treatments for Type One diabetes. In the deliberative workshop, the patients assumed (and were granted) authority over the other participants, with the result that the final 'consensus' was dominated by their views. By defining one group as having particularly relevant attributes, the role of others was diminished. Similarly, Smith and Wales (2000) argue against attempting to create a microcosm of the wider society in the deliberative forum because participants may then see themselves as defined and divided by demographic characteristics.

In our own work to specify a capability list in the context of equality and human rights monitoring for Britain, we ran 11 events with a total of 187 participants (for details see Burchardt and Vizard, 2011). We kept the size of each event relatively small (average group size 17 and maximum 32) to promote trust between participants and high-quality discussion, but we ran a sufficient number of events that people with a wide range of characteristics could participate, thus aiming to take on board both the 'deliberationist' and 'participationist' perspectives. In many cases, however, the final group size was determined more by the difficulty of recruitment than by the quality of 
discussion likely to ensue, and the total number of events was likewise affected by pragmatic considerations of time and cost.

Participants were recruited by Ipsos-MORI using telephone and on-street quota sampling. Three groups were drawn from the general public, in London, Edinburgh and Cardiff/Wrexham. The remaining groups were each drawn from a specific population: lesbian, gay and bisexual people; people with mobility impairments; people from ethnic minority groups; Pakistani women; Bangladeshi men; elderly people and carers; teenagers (age 13-16); children aged 9-12 and parents of younger children. ${ }^{3}$ Our aim was to include sufficient numbers of the general public to obtain a broadly representative picture, while at the same time ensuring that the particular experiences of groups believed to be at higher risk of discrimination or disadvantage were heard, steering a middle course, we hoped, between generalisability and marginalisation.

At least two value judgements were implicit in the design of our own work: that we would privilege the views of disadvantaged people as 'experts' on inequality and discrimination, but not to the exclusion of the views of the general public - a decision that gave rise to difficulties at the analysis and interpretation stage - and that the groups we identified as disadvantaged would be based on sex, ethnicity, disability, age, sexual orientation and religion (six of the 'protected grounds' in the 2006 Equality Act). ${ }^{4}$ The apparently technical question of participant selection therefore comes back to some fundamental issues: to what extent are participants viewed as citizens, capable of setting aside their individual identities and preferences to engage in public reasoning, to what extent are they viewed as experts, bringing their particular experiences (for example as users or patients or members of a minority group) to bear on the discussion, and to what extent are they viewed as self-interested individuals whose opinions need to be carefully weighed against each other to reach a final decision. Each view implies a distinct sampling strategy: for citizens, a small but random group - as in a criminal justice jury - is sufficient, for experts, purposive sampling is required with careful consideration of coverage and composition, while for participants viewed as self-interested individuals, a large-scale random survey is implied.

\section{Provision of evidence}

There is widespread recognition that informing participants without manipulating them is challenging. It is naïve to assume that information is just a tool for informing dialogue and not a source of power (Abelson et al, 2007). If the research aims to generate informed views, one must ask informed by whom and what? One response

In Newcastle, Stockport, Birmingham, Leicester, London and Bristol. The project also included a total of 15 interviews with people with sensory impairments; a Dyslexic person; Sikh, Muslim and Jewish people; and transgender people; but these are not discussed here since they were not part of the deliberative exercise.

Religion was not one of the selection criteria for the deliberative workshops but was reflected in the selection of interview respondents. 
proposed by Carson (2006) is that all briefing documents are agreed in advance with a carefully balanced steering group, but arguably this simply pushes the problem one step further back to the identification of appropriate 'balance' among members of the steering group.

Davies et al (2006) suggest that witnesses should be explicitly positioned rather than attempt to be neutral, and should include extreme views (although again, what constitutes an 'extreme view' is always relative to one's own position). But researchers may be caught in a cleft stick: participants are both doubtful about attempts to produce balanced information (as reported by Dienel, 1999, in relation to his Planning Cells) and critical of any perceived bias in witnesses (according to White et al's 1999 interviews with members of a citizens' jury). Deliberators know that information is always incomplete and partial, and are rightly wary of the material with which they are presented. In some studies, participants have been given the opportunity to call additional witnesses or ask for additional evidence, and this is apparently popular (Coote and Lenaghan, 1997; White, Lewis and Elam, 1999). However, a sense of incompleteness or a suspicion of bias is not the same as being able to detect a specific gap or slant, let alone know how to fill or correct it.

There is also a question of what qualifies as evidence. Academics are inclined to start from theories, tables and charts, but this is not always digestible to non-experts and may not be perceived as relevant. Barnes (2008) argues for the legitimacy of anecdotes and personal experience as a way to communicate issues, following Young's advocacy of the admissibility of rhetoric and story-telling (Young, 2000). But as Evans and Kotchetkova (2009) discovered, the inclusion of such material can act as an emotional veto over other perspectives and forms of reasoning, reducing the scope for effective deliberation.

In the pilots for our own deliberative workshops, we began by offering some basic statistics on inequality in Britain. However, these proved to be difficult to communicate and in any case highlighting inequality was not, it transpired, the best starting point for motivating a discussion about what it was important for people to be able to be and do in Britain today. Subsequently we developed a set of vignettes, based in part on real cases, of ways in which people's lives were constrained or impoverished. This proved more fruitful in terms of stimulating discussion about what was valuable in life. Participants were then invited to engage in two exercises. In the first, they were asked to develop, collectively, an account of what it meant to live a really good life in Britain today. In the second, we presented a list of central and valuable capabilities we had drawn up based on the international human rights framework, and asked participants to compare it to the list they had prepared in the first exercise, with a view to drawing up a final, considered, list of the things that everyone should be able to be and do.

In the event, there was considerable overlap between the lists generated by the first exercise and the list we presented for discussion in the second exercise, although our list was generally more extensive. But there is little doubt that the contents of our list 
was a significant influence on the overall outcome of the exercise. Had we presented a much more minimalist account of basic capabilities (for example, being adequately fed and sheltered and avoiding premature mortality) it is likely that participants would have expanded the list, but probably not to the full 10 domains covering economic, social and cultural as well as civil and political rights that finally emerged. The duration of our workshops (one- or half-day events) did not allow for participants to call for additional evidence or witnesses but it is not clear that they would have been in a position to know who or what to call to correct, or complement, the perspective our material brought to the exercise.

Participants' views often changed during the course of the workshop, for example, coming to appreciate that an aspect of life should be included in a capability list, where they had not previously considered it significant. For example, parents and older children did not spontaneously identify, 'developing the skills for participation in productive and valued activities, including parenting' as a central capability for children and young people, but strongly endorsed the inclusion of this item in the final list. The extent to which it was the material we presented to them and the extent to which it was encountering the views of others that was influential is hard to determine. In general, research on deliberative methods suggests that people do change their opinions, especially on less salient issues (Farrar et al, 2010; Hendriks, Dryzek, 2010).

To summarise, while the influence of the researcher's values on the nature of the written evidence presented and/or the witnesses that are called can be mitigated by the appointment of a steering group or by allowing participants to summon additional witnesses or evidence, it remains a significant factor. Whether or not the information deliberators receive plays a critical role in forming and transforming their views remains an open question, but to the extent that it is does, the researcher's own position will be an important determinant of the outcome.

\section{Nature of deliberation}

The extent to which deliberative exercises succeed in producing considered views depends in part on the nature of deliberation: the length of time allowed and the ways in which the discussion is structured and facilitated. Deliberations may last as little as a couple of hours or extend over several days. Citizens' juries tend to be held over 3 to 5 days, sometimes with a break in the middle to allow time for reflection (Coote and Lenaghan, 1997; Carson, 2006; White et al, 1999); deliberative polls take 2 days (Fishkin and Luskin 2005); large-scale deliberative summits are usually single day events (OLR 2005, 2006) and deliberative workshops may be half or one-day, with or without follow-up and/or reconvened groups. Clearly, a longer period of debate permits issues and views to be explored in greater depth, with potentially greater input from external experts and flexibility over the hearing of evidence, and greater engagement between participants. However, extended time commitments may be prohibitive for some participants, so researchers face a trade-off between duration of deliberation and inclusiveness (especially where participants are not reimbursed for their time). 
Elements of a deliberation include setting ground rules, introduction to the topic and purpose of the event, discussion of initial positions, hearing/reading and consideration of evidence, debate, and reaching a conclusion. These may be structured in various ways, with potentially several iterations between the evidence and debate stages. Many of the larger events include a mix of break-out groups and plenary sessions. The proportion of time allocated to the various elements depends in part on the complexity of the topic and the characteristics of participants (for example, whether they have been selected on the basis of their roles as patients, minority groups, etc, or whether they have all been recruited as 'citizens'), but is also a judgement which reflects the priorities of the researcher.

The facilitation of deliberative events is crucial, and requires different skills from those used in conventional focus groups, including an understanding of the distinctive purpose of deliberation (Coote and Lenaghan, 1997). There are risks associated with light-touch facilitation: for example, the emergence of discriminatory behaviour (Davies et al, 2006), or the domination of particular individuals or groups in the discussion (Evans and Kotchetkova, 2009). Agreeing rules of conduct at the outset can help (Smith and Wales, 2000) but does not remove the need for carefully-judged intervention. On the other hand, facilitation that is too heavy-handed threatens the legitimacy of the exercise and can be manipulative (Abelson et al, 2003).

One crucial decision in the design and facilitation of the deliberation is the degree of emphasis on reaching a consensus. Articulating and justifying differences of opinion is at the heart of public reasoning, and too great a push to reach a collective view can prematurely foreclose explorations of disagreement, and repress minority perspectives. Conversely, if the objective of agreeing a common position is not clearly present to the participants, a range of views may be expressed and set alongside each other, without any genuine engagement between them having taken place. A process that ends without reconciling any of the differences between participants has not fulfilled the purpose of a deliberative exercise.

Our own deliberative workshops were part- or full-day events, and were facilitated by independent professionals rather than by ourselves. The comparatively short duration of the events reflected our prioritisation of inclusiveness (a broad range of people participating) relative to depth of deliberation, given limited resources. Engaging with a fairly abstract topic, the selection of a capability list, even when described and explained in accessible and non-technical terms, was demanding for participants. Many started from thinking about what it was possible or realistic for people to be or do and found it difficult to make the leap to consider what it would be desirable, in public policy terms, for everyone to be able to be and do. Facilitation of the discussion and external the stimuli provided were therefore all the more important.

As described above, three of our workshops were drawn from the general public and the remainder were recruited on the basis of specific socio-demographic characteristics. This structure meant that for the most part, discussion took place within somewhat homogeneous groups, and had the advantage of providing a safer 
space in which normally minority perspectives could be explored and articulated (Young, 1989). For example, the workshop conducted with Pakistani women included several who were not confident English speakers and was carried out in Urdu - they would have been effectively excluded from a general public deliberation. Similarly, lesbian, gay and bisexual people may have felt more comfortable speaking out about issues of particular importance to them ('being able to be yourself in a public place' was suggested as an addition to the capability list by this group) because they were in a workshop specifically for them. However this aspect of the design of most of our workshops also meant that engagement with the views of others was limited to others who shared a particular characteristic, which both artificially boosted the salience of that characteristic in the discussion, and meant that it fell to the researchers to integrate the conclusions arising from the different population subgroups, rather than that function being performed within the workshops themselves. This is an illustration of the tension between recognising (and seeking to redress) imbalances of power and representation, and providing a single forum in which differences can be examined and subject to critical scrutiny from a full range of participants.

\section{Analysis and interpretation}

Where a clear consensus or decision has been reached, the role of the researcher in analysis and interpretation is limited (Evans and Kotchetkova, 2009). However, in the case of large-scale exercises, some aggregation or analysis by sub-group is likely to be necessary (Dienel, 1999; Orr, 2007). Crocker (2003) encourages attention to disagreement within the group including dissent which may not be verbalised as such, and placing emphasis in the report on the process as well as the outcome (Van Stokkom, 2005; White et al, 1999). Davies et al (2006) recommend that where there are unresolved disagreements, facilitators should produce a report giving an account of the reasoning behind the different conclusions. Ideally, any report should be checked with the participants to ensure it is an accurate reflection of their views, although this can be difficult if views change once participants are back in the real world'.

Depending on the objective of the research, there may also be interest in comparing the views of participants pre and post deliberation, to assess the extent to which the evidence provided, together with the discussion between participants, changed people's views. This is built into the structure of Fishkin and Luskin 's Deliberative Polls and is a feature of a number of other deliberative projects. Understanding the extent to which values are fixed, or are subject to transformation through information and discussion, may be informative in itself.

Where multiple events are held, as in our own work, researchers necessarily have a role to play in combining and interpreting the results. Differences in outcomes between groups can simply be reported as such, but if the objective is to identify a common position (for example, an agreed poverty threshold or capability list), some procedure for combining results is needed. In our case, we adopted a simple 'accumulation' rule: if a capability was cited by any group as being central and valuable to life in Britain today, it was included in the final capability list, even if it 
was not specified by all groups. This ensured that capabilities highlighted by some of the groups at particular risk of discrimination and disadvantage, but not mentioned by the general public groups, featured in the final capability list. The 'accumulation rule' was transparent and straightforward to apply but we were greatly helped by the objective being to create a comprehensive capability list and therefore having no predetermined limit on its length. Had the exercise been intended to prioritise amongst capabilities on the list, or to produce a much more restricted list, the decision rule for combining results from multiple events would have required a judgement, for example, about the weight to be accorded to the views of minority groups.

\section{Summary}

The distinctive objective of deliberative research is to elicit a considered, informed collective value judgement from the general public. In delivering this objective, researchers confront a series of methodological challenges: the selection of participants (whose considered views?), the provision of evidence (informed by what?), the structure of the deliberation (considered through what process?) and the analysis of potentially conflicting results (what constitutes a collective judgement?) At each point, apparently technical methodological questions are found to embed substantial normative considerations. The consequences for the use of deliberative research are considered in the next section.

\section{Discussion}

The 'deliberative turn' in democratic theory has generated a wealth of deliberative projects and experiments. Research in this context is often conflated with policymaking, consultation and stand-alone public engagement exercises, yet the purpose of deliberation as a research technique is distinctive. The primary function of research is to contribute to knowledge and understanding - in this case, uncovering the public's values - rather than to bring intrinsic or instrumental democratic benefits, or to influence policy. Of course, some of these benefits may arise as byproducts of deliberative research, but the evaluation of research as research needs to be based on criteria such as transparency, reliability and validity, and not on its contribution to democratic legitimacy or accountability.

So, when is deliberative research appropriate? We have seen it is particularly wellsuited to situations where the challenge is to identify an informed, considered, and collective view. In the social science context, this often arises in relation to research on poverty, well-being and inequality, where there is a need to define and justify the thresholds and concepts adopted on a deeper basis than convention alone can offer. This application is of course closely related to the theoretical origins of deliberative research in democratic theory, with its emphasis on public reasoning.

Comparing deliberative research to more traditional methods of studying the values of the general public, such as in-depth interviewing, attitudinal surveys, and participatory approaches, reveals that adopting a deliberative research design involves a number of 
epistemological and normative assumptions. It implies a distinction between facts about the world, which can be illuminated by reference to external experts, and the real values of the participants (and the public in general), which can be ascertained only through discussion and interaction between people. Thus it shares the positivist assumptions of large-scale surveys in relation to 'facts' but the interpretativist view more usually associated with in-depth interviewing and ethnography when it comes to values. In common with participatory approaches, it emphasises a collective process, but while the participatory paradigm champions insider expertise - the lived experience of the disadvantaged, for example - in deliberative research, the injection of information, including through use of external experts, is regarded as an essential ingredient. Finally, while much social research on values seeks to explore and explain differences, deliberative research prioritises the search for a consensus or a collective decision.

Putting deliberative research into practice involves making another set of judgements, including trade-offs between quality and quantity of deliberation, between representativeness and inclusiveness, between treating participants as citizens or as representatives of groups with particular experiences and characteristics, between redressing power imbalances through protected space for disadvantage groups and integrating diverse perspectives in a single forum, and between recognising dissent and promoting consensus.

Normative decisions therefore permeate the design and implementation of deliberative research, so while it certainly has a unique contribution to make, it by no means lets researchers 'off the hook' of making value judgements. Rather the judgements move from the outcome (what poverty threshold should we use) to the process (adopting a deliberative paradigm and setting the parameters of the debate). As with any technique, the appropriateness of deliberative research depends on clarity in the reasons for using the approach, the goodness of fit between the research question and the tool in hand, and on how the tool is used. For the purposes of defining a collective position on normative questions in social science, such as a poverty threshold or capability list, it has the potential to provide uniquely considered, insightful and welljustified answers - but transparency at all stages of the process is essential if the charge of being simply a mirror of the researcher's own values is to be avoided. 


\section{References}

Abelson, J., Forest, P., Eyles, J., Smith, P., Martin, E., and Gauvin, F.-P. (2003) "Deliberations about deliberative methods: issues in the design and evaluation of public participation processes", Social Science and Medicine, 57 (2): 239251.

Abelson, J., Forest, P., Eyles, J., Casebeer, A., Martin, E., and Mackean, G. (2007) "Examining the role of context in the implementation of a deliberative public participation experiment: Results from a Canadian comparative study", Social Science \& Medicine, 64(10), 2115-2128.

Alkire, S. (2002) Valuing freedoms : Sen's capability approach and poverty reduction. Oxford: Oxford University Press.

Barnes, M. (2008) "Passionate participation: emotional experiences and expressions in deliberative forums", Critical Social Policy, 28: 461-481.

Baiocchi, G. (2003) "Participation, activisim and politics: the Porto Alegre experiment". In A. Fung and E. Wright (eds) Deepening Democracy: institutional innovations in empowered participatory governance. London: Verso.

Bennett, W, Pickard, V., Iozzi, D., Schroeder, C., Lagos, T. and Caswell, E. (2004) "Managing the public sphere: journalistic construction of the great globalisation debate", Journal of Communication, 54 (3): 437-456.

Burchardt, T., Le Grand, J. and Piachaud, D. (1999) "Social exclusion in Britain, 1991-1995”, Social Policy \& Administration, 33 (3): 227-244.

Burchardt, T. and Vizard, P. (2011) "Foundations for equality and human rights monitoring in 21st century Britain", Journal of Human Development and Capabilities, 12 (1): 91-119.

Cabinet Office (2006) Viewfinder: A Policy Maker's Guide to Public Involvement. London: Cabinet Office.

Carson, L. (2006) "Improving Public Deliberative Practice: A Comparative Analysis of Two Italian Citizens' Jury Projects in 2006", Journal of Public Deliberation, 2(1): article 12.

Chambers, R. (1997) Whose Reality Counts? Putting the first last. London: Intermediate Technology.

Chilvers, J. (2008) "Deliberating competence: theoretical and practitioner perspectives on effective participatory appraisal practice", Science, Technology and Human Values, 33 (3): 421-451.

Coote, A., Lenaghan, J., and Institute for Public Policy Research. (1997). Citizens' Juries: theory into practice. London: Institute for Public Policy Research.

Crocker, D. (2003) Participatory Development: the Capabilities Approach, and Deliberative Democracy. University of Maryland. 
Crocker, D. (2006) "Sen and deliberative democracy", in A. Kaufman (ed) Capabilities Equality: basic issues and problems. London: Routledge.

Crocker, D. (2007) "Deliberative participation in local development", Journal of Human Development, 8 (3): 431-455.

Davies, C., Wetherell, M., and Barnett, E. (2006). Citizens at the Centre: Deliberative Participation in Healthcare Decisions. Bristol: Policy Press.

de Sousa Santos, B. (2005) "Participatory Budgeting in Porto Alegre: Toward a Redistributive Democracy”. In B. De Sousa Santos (ed), Democratizing Democracy: Beyond the Liberal Democratic Canon. London: Verso.

Dean, H. (2009) "Critiquing capabilities: the distractions of a beguiling concept", Critical Social Policy, 29 (2): 261-273.

Department for Work and Pensions (2006) National Pensions Debate http://www.dwp.gov.uk/docs/npdfinal.pdf

Dienel, P. (1999) "Planning Cells: the German Experience". In U. Khan (ed), Participation Beyond the Ballot Box: European Case Studies in State-Citizen Political Dialogue. London: UCL Press.

Dryzek, J. (2010) Foundations and Frontiers of Deliberative Governance. Oxford: OUP.

Evans, E. and Kotchetkova, I. (2009) "Qualitative research and deliberative methods: promise or peril?”, Qualitative Research, 9: 625-643.

Fabian Society (2005) Why life chances matter: the interim report of the Fabian Commission on Life Chances and Child Poverty. London: Fabian Society.

Farrar, C., Fishkin, J., Green, D., List, C., Luskin, R. and Paluck, E. (2010) "Disaggregating deliberation's effects: an experiment within a deliberative poll”, British Journal of Political Science, 40 (2); 333-347.

Fishkin, J. and Luskin, R. (2005) "Experimenting with a Democratic Ideal: Deliberative Polling and Public Opinion”, Acta Politica, 40, 284-298.

Fishkin, J. (2009) When the People Speak: deliberative democracy and public consultation. Oxford: Oxford University Press.

Fishkin, J. (2010) "Consulting the public thoughtfully: prospects for deliberative democracy". In D. Kahane, D. Weinstock, D. Leydet and M. Williams (2010) (eds) Deliberative Democracy in Practice. Vancouver: UBC Press.

Fraser, N. (1989). Unruly Practices: Power, discourse and gender in contemporary social theory. Minneapolis: University of Minnesota Press.

Gordon, D. (2006) "The concept and measurement of poverty". In C. Pantazis, D. Gordon and R. Levitas (eds) Poverty and Social Exclusion in Britain: the millennium survey. Bristol: Policy Press.

Gutmann and Thompson (1996) Democracy and Disagreement. Cambridge, MA: Harvard University Press 
Habermas, J. (1988) [1967] On the Logic of the Social Sciences. Oxford: Polity.

Habermas, J. (1996). Three normative models of democracy. In S. Benhabib (ed)

Democracy and Difference: contesting the boundaries of the political.

Princeton, NJ: Princeton University Press.

Involve and National Consumer Council (2008) Deliberative Public Engagement: nine principles. London: National Consumer Council

IpsosMORI (2007) Consulting for a Capability List

http://webarchive.nationalarchives.gov.uk/20100807034701/http://archive.cabi netoffice.gov.uk/equalitiesreview/upload/assets/www.theequalitiesreview.org.u k/morireport.pdf (accessed 03/04/2012)

Lenaghan, J. (1999) "Involving the public in rationing decisions. The experience of citizens juries", Health Policy, 49 (1-2): 45-61

Michels, A. (2011) "Innovations in democratic governance: how does citizen participation contribute to a better democracy", International Review of Administrative Sciences, 77: 275-293.

Narayan, D. (2000) Voices of the Poor: crying out for change. New York: Oxford University Press..

Narayan, D., Pritchett, L. and Kapoor, S. (2009) Moving Out of Poverty: success from the bottom up. Washington: World Bank

Nussbaum, M. (2002) Women and Human Development: the capabilities approach. Cambridge: Cambridge University Press

Opinion Leader Research (2005) Preliminary Report of Citizens' Summit. http://www.dh.gov.uk/en/News/Yourhealthyourcareyoursay/DH_4122298 (accessed 03/04/2012)

Opinion Leader Research (2006) DWP National Pensions Debate Final Report. London: Department for Work and Pensions.

Opinion Leader Research (2007) Better Engagement, Better Decisions Seminar, 29 November, London.

Orr, S. (2007) "Values, preferences and the citizen-consumer distinction in cost benefit analysis", Politics, Philosophy and Economics, 6 (1): 107-130.

Parkinson, J. (2006) Deliberating in the Real World: Problems of Legitimacy in Deliberative Democracy. Oxford Scholarship Online.

Papadapoulos, Y. and Warin, P. (2007) "Are innovative, participatory and deliberative procedures in policy making democractic and effective?", European Journal of Political Research, 46: 445-472.

Parkinson, J. (2006) Deliberating in the Real World: Problems of Legitimacy in Deliberative Democracy. Oxford Scholarship Online.

Rawls, J. (1997) “The idea of public reason revisited”, University of Chicago Law Review, 64 (3): 765-807. 
Richardson, H. (2002) Democratic Autonomy: public reasoning about the ends of policy. Oxford: Oxford University Press.

Rowe, G. and Frewer, L. (2005) "A typology of public engagement mechanisms", Science, Technology and Human Values, 30 (2): 251-290.

Rowe, G., Horlick-Jones, T., Walls, J. and Pidgeon, N. (2005) "Difficulties in evaluating public engagement initiatives: reflections on an evaluation of the UK 'GM Nation?' public debate about transgenic crops", Public Understanding of Science, 14 (4): 331-352.

Searing, D., Solt, F., Conover, P. and Crewe, I. (2007) "Public discussion in the deliberative system: does it make better citizens?", British Journal of Political Science, 37: 587-618.

Sen, A. (1999) Development as Freedom. Oxford: Oxford University Press.

Smith, G., and Wales, C. (2000). “Citizens'Juries and Deliberative Democracy”, Political Studies, 48(1), 51-65.

Trinczek, R. (2007) "Income poverty in the European Union”, European Foundation for the Improvement of Living and Working Conditions working paper http://www.eurofound.europa.eu/ewco/surveyreports/EU0703019D/EU070301 9D.pdf (accessed 09/03/2012)

Van Stokkom, B. (2005) "Deliberative group dynamics: power, status and affect in interactive policy making", Policy and Politics, 33 (3): 387-409.

Wakeford, T. (2007) "The jury is out: How far can participatory projects go towards reclaiming democracy?" In P. Reason \& H. Bradbury (eds) The SAGE Handbook of Action Research: Participative Inquiry and Practice (2nd ed.). London: Sage Publications.

Wakeford, T. and Singh, J. (2008) "Towards empowered participation: stories and reflections", Participatory Learning and Action, 58 (June): 6-9 and 51-2.

Weinstock, D. and Kahane, D. (2010) “Introduction”. In D. Kahane, D. Weinstock, D. Leydet and M. Williams (eds) Deliberative Democracy in Practice. Vancouver: UBC Press.

White, C., Lewis, J. and Elam, G. (1999). Citizens' Juries: An appraisal of their role based on the conduct of two women only juries. London: Cabinet Office.

Young, I. (1989). "Polity and Group Difference: A Critique of the Ideal of Universal Citizenship", Ethics, 99, 250-274.

Young, I. (2000) Inclusion and democracy. New York: Oxford University Press. 